\title{
LABSAMPA - COOPERAÇÃO CIENTÍFICA E TECNOLÓGICA ENTRE A FACULDADE DE ARQUITETURA E URBANISMO DA UNIVERSIDADE DE SÃO PAULO E O DIPARTIMENTO DI ARCHITETTURA DELL'UNIVERSITÀ DEGLI STUDI DI FIRENZE PARA A DOCUMENTAÇÃO DA ARQUITETURA HISTÓRICA DE SÃO PAULO \\ LABSAMPA - SCIENTIFIC AND TECHNOLOGICAL COOPERATION BETWEEN THE FACULDADE DE ARQUITETURA E URBANISMO DA UNIVERSIDADE DE SÃO PAULO AND THE DIPARTIMENTO DI ARCHITETTURA DELL'UNIVERSITÀ DEGLI STUDI DI FIRENZE FOR THE DOCUMENTATION OF THE HISTORICAL ARCHITECTURE IN SÃO PAULO
}

\author{
Luciano Migliaccio ${ }^{1}$, Stefano Bertocci ${ }^{2}$, Beatriz Piccolotto Siqueira Bueno ${ }^{1}$, Regina \\ Helena Vieira Santos ${ }^{3}$, Renata Maria de Almeida Martins ${ }^{1}$
}

\section{RESUMO:}

Desde 2017 a Faculdade de Arquitetura e Urbanismo da Universidade de São Paulo e o Dipartimento di Architettura da Università degli Studi di Firenze desenvolvem um projeto de cooperação didática e científica com uso de tecnologia laser scanner 3D para a elaboração de documentação histórica do patrimônio arquitetônico no centro de São Paulo. O projeto levou à realização de laboratórios teórico-práticos e à criação de uma disciplina optativa de graduação voltada para a inserção dos resultados da cooperação acadêmica dentro da oferta formativa das duas instituições. A iniciativa, com a participação de uma equipe italiana e de uma brasileira, formadas por docentes, pesquisadores e alunos de graduação e de pós-graduação, já auxilia a produção de trabalhos finais de graduação e de pesquisas de mestrado e doutorado nas duas instituições. Neste texto serão apresentados três casos de estudo de edifícios históricos do centro de São Paulo, que foram objetos dos laboratórios: o Edifício Baraúna, na Avenida São João, a Sucursal do Grande Hotel no Largo do Café, o Solar da Marquesa de Santos, sede do Museu da Cidade de São Paulo, na Rua Roberto Simonsen. Por meio de levantamento realizado com tecnologia laser scanner $3 \mathrm{D}$, integrado com método fotogramétrico e métrico manual, foi possível implementar uma metodologia de documentação histórica capaz de contribuir para a abertura de novas perspectivas historiográficas e servir como subsídio para o estúdio e o planejamento de ações de preservação, restauro e reutilização do patrimônio edificado. PALAVRAS-CHAVE: Levantamento digital; Tecnologia Laser Scanner 3 D; Preservação do patrimônio arquitetônico.

\begin{abstract}
:
Since 2017, the Faculty of Architecture and Urbanism of the University of São Paulo and the Dipartimento di Architettura of the Università degli Studi di Firenze have developed a didactic and scientific cooperation project with the use of $3 \mathrm{D}$ laser scanner technology for the preparation of historical documentation of architectural heritage in center of Sao Paulo. The project led to the realization of theoretical-practical laboratories and the creation of an optional undergraduate course aimed at inserting the results of academic cooperation within the training offer of the two institutions. The initiative, with the participation of an Italian and a Brazilian team, made up of professors, researchers and undergraduate and graduate students, already assists in the production of final undergraduate and master's and doctoral research work at both institutions. In this text, three case studies of historic buildings in the center of São Paulo, which were the objects of the laboratories, will be presented: the Edifício Baraúna, on Avenida São João, the Sucursal do Grande Hotel in Largo do Café, the Solar da Marquesa de Santos, headquarters of the Museum of the City of São Paulo, at Rua Roberto Simonsen. Through a survey carried out with laser scanner technology 3D, integrated with photogrammetric and manual metric method, it was possible to implement a methodology of historical documentation capable of contributing to the opening of new historiographic perspectives and serving as a subsidy for the studio and the planning of actions of preservation, restoration and reuse of the architectural heritage. KEYWORDS: Digital architectural survey; Laser Scanner 3 D Technology; Protection of the architectural heritage
\end{abstract}

How to cite this article:

MIGLIACCIO, L. et. al. LABSAMPA - cooperação científica e tecnológica entre a Faculdade de Arquitetura e Urbanismo da Universidade de São Paulo e o Dipartimento di Architettura dell'università degli Studi di Firenze para a documentação da arquitetura histórica de São Paulo. Gestão \& Tecnologia de Projetos. São Carlos, v16, n3, 2021. https://dx.doi.org/10.11606/gtp.v16i3.174890.
${ }^{1}$ Universidade de São Paulo. Faculdade de Arquitetura e Urbanismo.

2 Università di Firenze, Dipartimento di Architettura

${ }^{3}$ Municipalidade de São Paulo. Departamento de Patrimônio Histórico, Faculdade de Arquitetura e Urbanismo da Universidade de São Paulo

Fonte de Financiamento: Universidade de São Paulo.

Conflito de Interesse: Declara não haver.

Ética em Pesquisa: Declara não haver necessidade.

Submetido em: 18/09/2020 Aceito em: 11/02/2021 


\section{INTRODUÇÃO}

A iniciativa de cooperação científica ítalo-brasileira "LabSAMPA - Laboratório de documentação da arquitetura histórica em São Paulo" surgiu em 2017 a partir do estágio realizado junto ao Dipartimento di Architettura dell'Università degli Studi di Firenze pela Dra. Regina Helena Vieira Santos, durante pesquisa de doutorado sobre a história urbana da Avenida São João, orientada pelo prof. Luciano Migliaccio, junto ao Programa de Pós-graduação da Faculdade de Arquitetura e Urbanismo da Universidade de São Paulo. A pesquisa contou com um intercâmbio com instituição florentina, sob a direção do prof. Silvio Van Riel, e a colaboração do professor Stefano Bertocci. Durante a estada da Dra. Vieira Santos na Itália, alguns alunos de graduação e pesquisadores da área de levantamento digital, manifestaram interesse em realizar o escaneamento digital 3D de um trecho da Avenida São João envolvido no alargamento realizado durante as primeiras duas décadas do século XX. Dentro deste recorte, foi selecionado como objeto de estudo o Edifício Baraúna, palacete de uso comercial projetado pelo engenheiro português Ricardo Severo em 1923, que se destaca pela novidade das soluções construtivas em relação à média das construções do mesmo tipo realizadas em São Paulo à época, junto com a adoção de um repertório decorativo neocolonial nas fachadas.

Figura 1. Desenho realizado para a tese de graduação de Anastasia Cottini e Chiara Alessi sob o título: "Avenida São João un rilievo urbano nel centro storico di São Paulo, Brasile", prancha 4, seções longitudinais, julho 2018. Fonte: Acervo da Pesquisa.

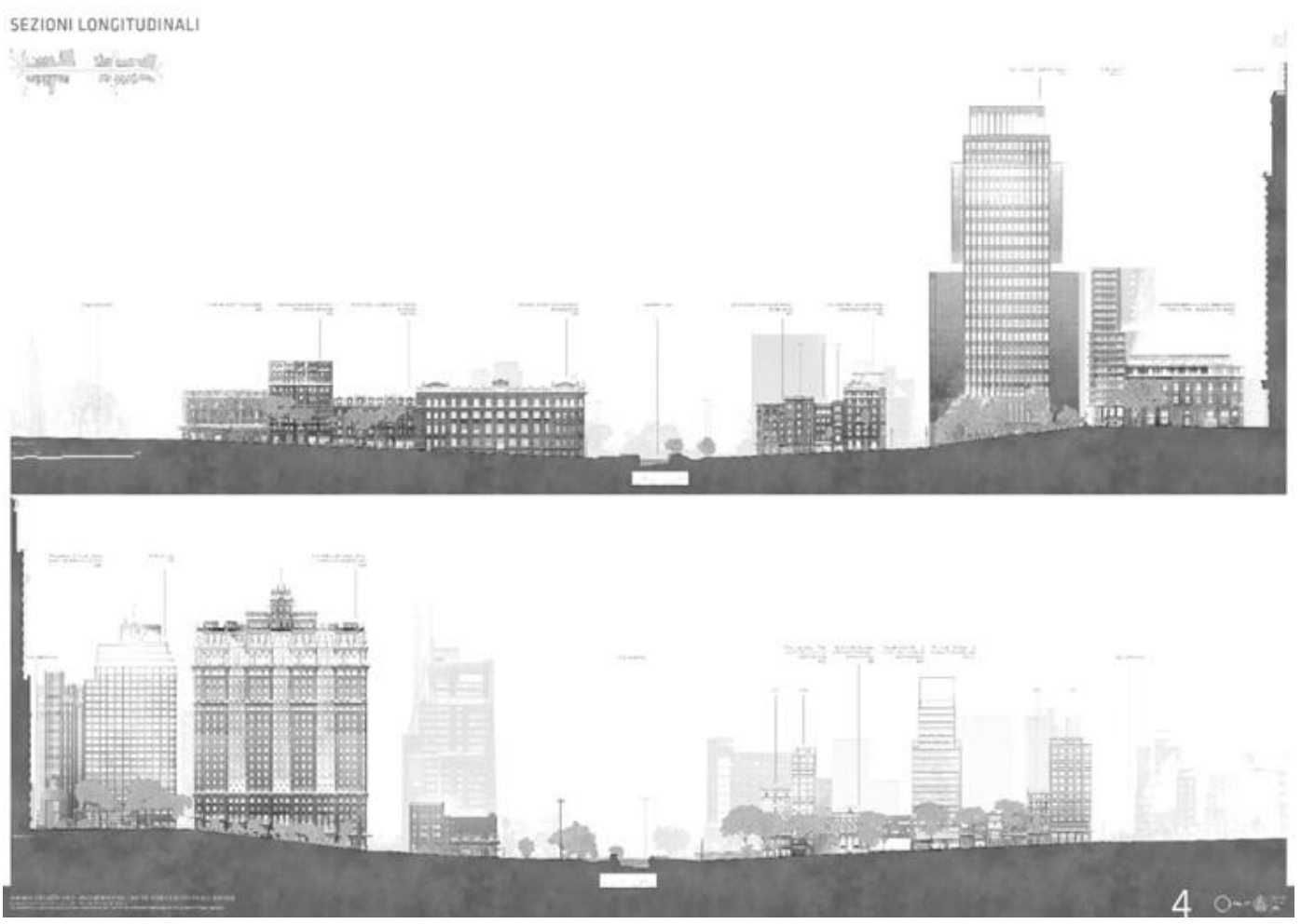




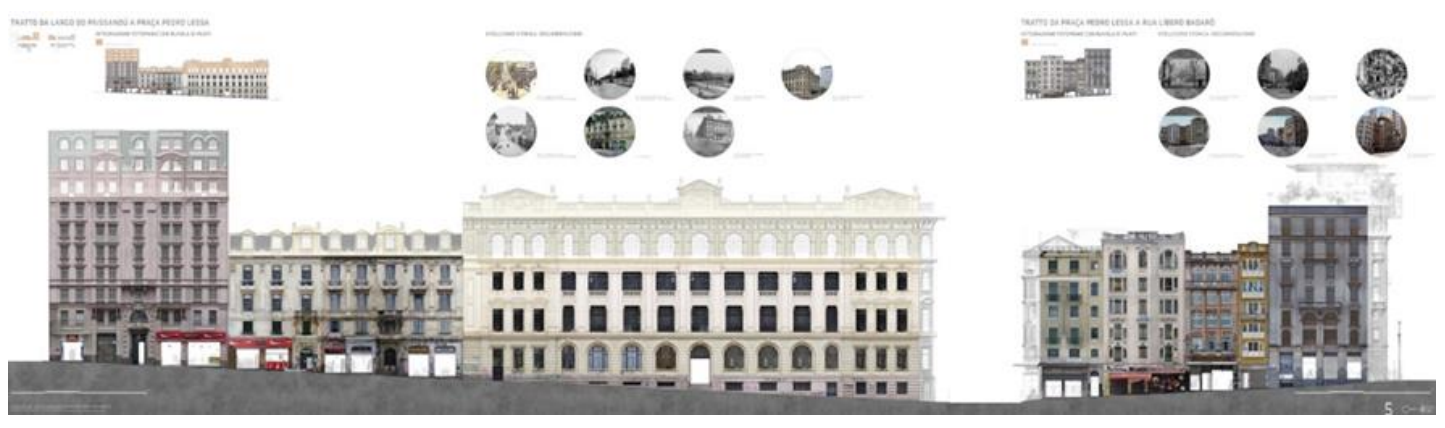

O levantamento do edifício foi realizado em setembro de 2017, no formato de um workshop livre, com a participação de uma equipe italiana composta pelas estudantes Anastasia Cottini e Chiara Alessi, e os pesquisadores Matteo Bigongiari, Monica Bercigli, Pietro Becherini, sob coordenação do Professor Stefano Bertocci, e de alunos matriculados nos Cursos de Graduação e de Pós-graduação da FAU USP.

Os resultados das atividades do workshop com carga de 100 horas/aula foram positivos, evidenciando a importância da continuação das atividades envolvendo alunos de graduação da FAU USP, para introduzir os métodos de levantamento digital com tecnologia 3D adotados pela instituição florentina no âmbito da oferta formativa proporcionada pela faculdade brasileira.

Desde o segundo semestre de 2018, a disciplina optativa AUH 237 Urbanização e Urbanismo ou no Brasil, do curso de graduação da Faculdade de Arquitetura e Urbanismo da Universidade de São Paulo passou a incluir uma atividade de cooperação prática entre a escola brasileira e o Dipartimento di Architettura dell'Università di Firenze. A partir deste ano de 2020, a atividade forma parte da nova disciplina optativa AUH 335 "LABSAMPA: laboratório de documentação da arquitetura histórica de São Paulo", do Curso de Graduação da FAU USP.

Os professores responsáveis Beatriz Piccolotto Siqueira Bueno e Luciano Migliaccio, com a colaboração da Dra. Regina Helena Vieira Santos do Departamento de Patrimônio Histórico da Prefeitura Municipal de São Paulo e do doutorando Rodrigo Luiz Minot Gutierrez, realizaram um projeto didático interdisciplinar, com a participação de alunos do Curso de Graduação em Arquitetura e Urbanismo da FAU USP, da Escola Politécnica e do Dual Training Program das duas faculdades, novamente em colaboração com pesquisadores e recém-formados da Universidade de Florença, sob orientação do professor Stefano Bertocci.

O objetivo do curso foi combinar trabalho de campo e dimensão teórico-metodológica da atividade de levantamento, a fim de instruir os alunos ao uso de tecnologia digital com scanner a laser 3D na preparação de documentação para projetos de, preservação restauração e reutilização de edifícios históricos. Com particular atenção ao centro da cidade de São Paulo, a disciplina apresentou e discutiu teorias e metodologias de documentação para o estudo da história da urbanização e da arquitetura em suas relações com a arqueologia e a cultura material.

Alguns estudos de caso foram selecionados para experimentar métodos de integração da tecnologia digital laser scanner 3D com dados do levantamento métrico e fotogramétrico. A experiência de campo no centro histórico de São Paulo ajudou a aprofundar nos estudantes a compreensão da evolução histórica do ambiente urbano e a função fundamental dos registros históricos para a proteção de bens culturais. 0 programa incluiu atividades de campo intensivas concentradas ao longo de uma semana. Em tal período, foi realizado o exame de um edifício selecionado, por meio de processamento informático de dados do levantamento digital e sua integração com os da métrica de detecção manual e da detecção por meio de fotografia e fotogrametria. Tal conjunto de dados serviram como suporte para a produção de desenhos documentando os resultados finais da disciplina.
Figura 2. Desenho realizado para a tese de graduação de Anastasia Cottini e Chiara Alessi sob o título: "Avenida São João um rilievo urbano nel centro storico di São Paulo, Brasile", prancha 5, tratamento das fachadas entre 0 Largo Paissandú e a Rua Líbero Badaró, julho 2018. Fonte: Acervo da Pesquisa. 
O levantamento métrico manual foi realizado com o objetivo de compreender melhor o espaço estudado e integrar as lacunas nos dados detectados pela varredura digital. Para a representação dos prospectos, foi realizada fotogrametria com o software PhotoScan, utilizando imagens sequenciais da parte externa do edifício, o que permite o levantamento dos elementos geométricos tridimensionais fotografados. Para as partes inacessíveis das fachadas, foi utilizado um drone DJI Spark. Por fim, o modelo obtido a partir da nuvem de pontos produzida pela digitalização a laser 3D foi sobreposto a esses dados, a fim de especificar as dimensões das partes que compõem a fachada.

Terminado o processo de levantamento, os alunos, divididos em grupos, procuraram a documentação histórica relativa aos edifícios selecionados existente nos arquivos. Os resultados dos exames empíricos e do estudo histórico foram reunidos nos seguintes tópicos:

- 0 contexto urbano, topografia, implantação, proprietários e plantas;

- $\quad 0$ arquiteto, os construtores e a datação do projeto; Análise dos projetos;

- Questões tectônicas. Materiais e técnicas construtivas das várias partes do edifício;

- Linguagem estética: do conjunto aos acabamentos.

Além dos prédios históricos da cidade, a partir dos estudos da arquiteta Regina Helena Vieira Santos, em harmonia com aqueles promovidos pelo projeto Jovem Pequisador "Barroco Cifrado", financiado pela FAPESP (Fundação de Amparo à Pesquisa do Estado de São Paulo), coordenado pelo prof. Renata Maria de Almeida Martins, foram objeto de levantamento digital significativas construções do período colonial no litoral do Estado de São Paulo, isto é: as ruínas do assentamento conhecido como o Sítio do Abaré Bebê, no município de Peruíbe, e o conjunto arquitetônico da Igreja e Convento de Nossa Senhora da Conceição, e da Igreja Matriz de Santana, no município de Itanhaém.

Os resultados obtidos com a aplicação dessas metodologias de detecção arquitetônica e histórica, destacando as possibilidades educacionais do uso da tecnologia na comunicação ao público do valor dos edifícios como um documento da história urbana, levaram em 2020 à assinatura de um acordo de cooperação entre a Faculdade de Arquitetura e Urbanismo e o Museu da Cidade de São Paulo, órgão da Secretaria da Cultura da Municipalidade de São Paulo.

Como veremos, as edificações escolhidas como estudos de caso foram selecionadas não tanto pelo seu significado como monumentos históricos, mas, acima de tudo, pela sua importância para a história do desenvolvimento urbano da cidade, das técnicas e da indústria da construção. Segue abaixo a descrição de alguns casos de estudos selecionados. 


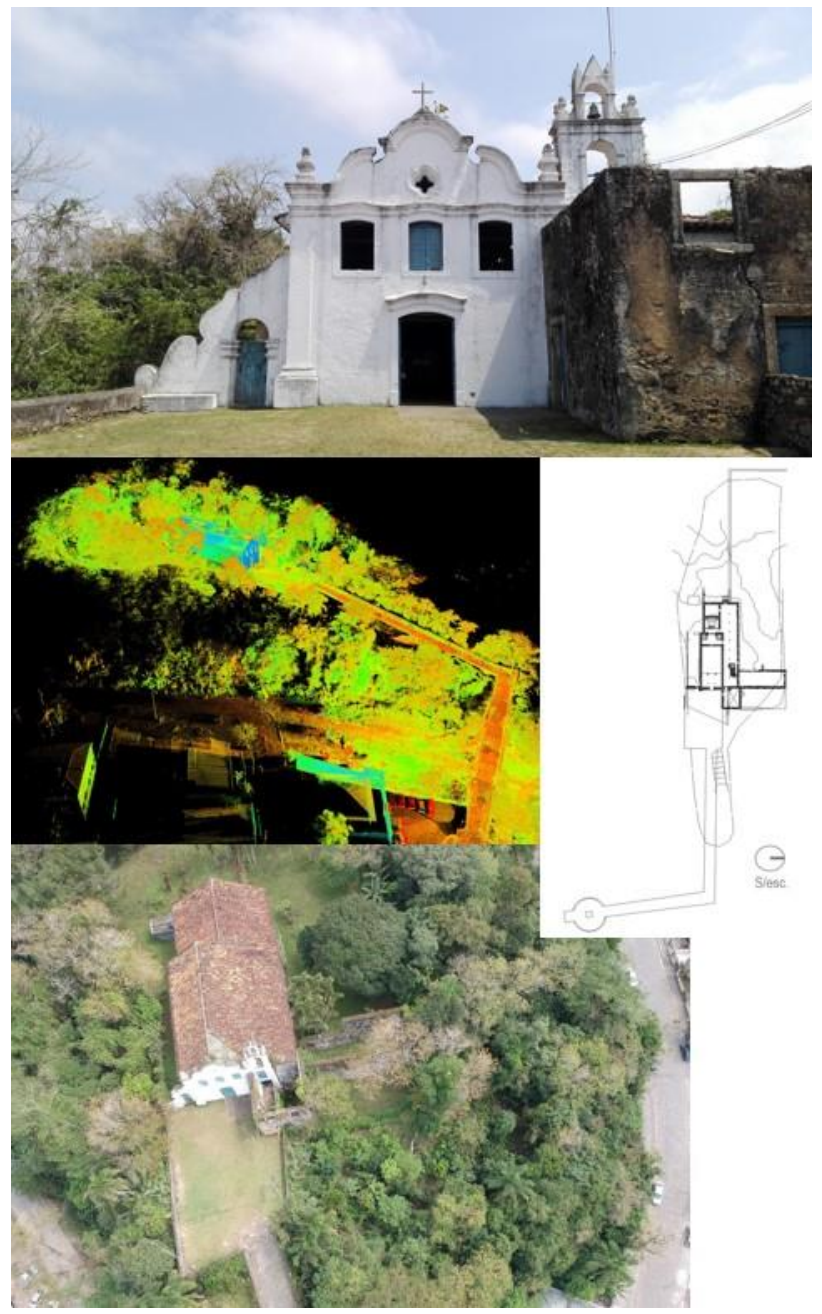

Figura 3. Vistas do Conjunto Arquitetônico das Ruínas do Convento e Igreja da Conceição de Itanhaém. Fotografia de Regina Helena Vieira Santos, 2017. Nuvem de pontos gerada do escaneamento digital 3D feito em 2017; foto aérea feita com o Drone por Pietro Becherini em 2018. Desenho da planta feita sobrepondo o desenho do levantamento métrico feito in loco em 2005, com 0 desenho feito utilizando a nova tecnologia em 2017.

Fonte:

Acervo da Pesquisa.

\section{EDIFÍCIO BARAÚNA}
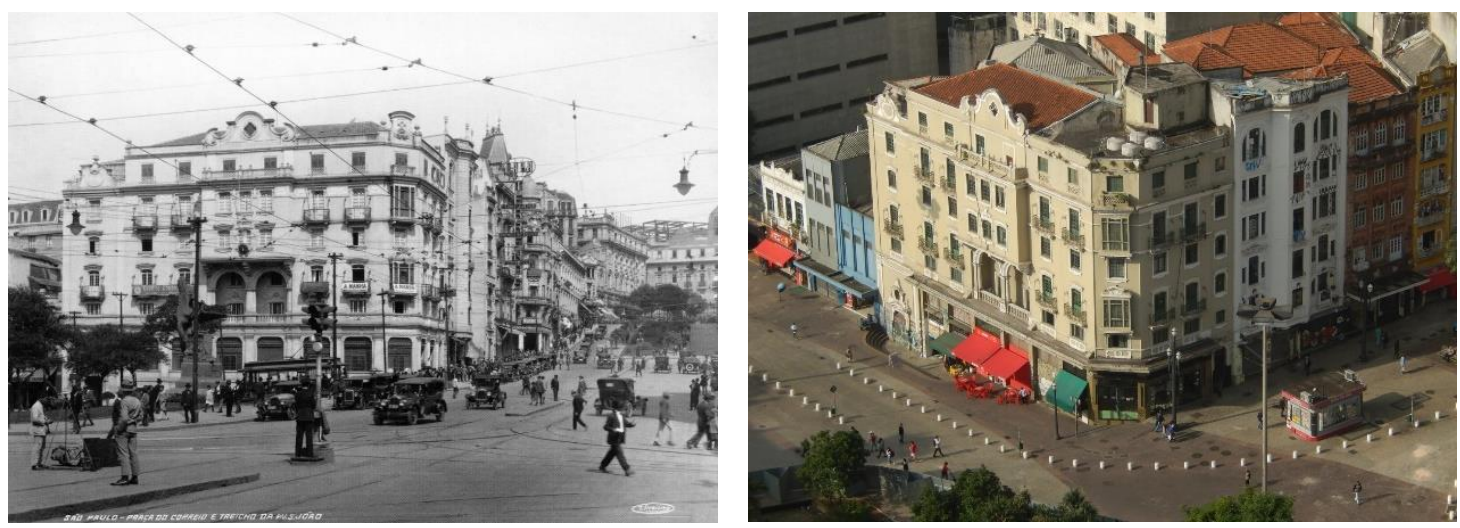

Figura 4. A) Edifício Baraúna, vista da fachada para o Vale do Anhangabaú, 1926, Fonte: cartão postal de Theodor Preising, acervo Regina Helena Vieira Santos.

B) Vista aérea do Edifício Baraúna, 2018,

Fonte: foto de Regina Helena Vieira Santos. 
O "Edifício Baraúna", assinado pelo engenheiro Ricardo Severo foi construído no ano de 1923. A estrutura em concreto armado e alvenaria de tijolos é revestida com argamassa raspada denominada de pedra fingida. As esquadrias são de madeira e vidro. 0 piso térreo é todo comercial, como também o porão que, decorrente da topografia, faz frente voltada para o Vale do Anhangabaú.

Conforme as plantas originais, a circulação vertical está resolvida por dois acessos independentes, um pela Avenida São João, no atual número 126, e o outro pelo Vale do Anhangabaú (Praça do Correio), ambos sem limite com a edificação vizinha. Para o arejamento e iluminação de todos os ambientes, há um poço interior. 0 porão, acessado pelas escadas, é formado por um espaço único. 0 piso térreo possui um acesso independente pela Avenida São João. Projetado para ser armazém, há muitos anos é sede do histórico Restaurante Guanabara. O piso da sobreloja possui salas de escritório, banheiros, "lodge", e o elevador definido de "ascensor", com um curioso italianismo.

0 primeiro andar em planta é igual à sobreloja. No segundo andar, os ambientes eram destinados para bilhar e outros jogos de mesa. Um destes espaços medindo 8,00 m por 5,60 m era denominado " bacará " enquanto os cômodos voltados para a Avenida, eram para " restaurante ", " buffet ", "cosinha " e " toilete " e " wc ". No terceiro piso próximo ao acesso da Avenida há o corredor de distribuição para banheiros, um cômodo para guarda-roupa, uma sala voltada para o chanfro, um grande salão com palco que acessa o terraço na cobertura do edifício. 0 ático faz pé direito duplo para o salão, oferecendo balcão em todo o entorno voltado para o palco. Também há dois banheiros, um para sala de secretaria e outro para diretoria, no chanfro.

As envasaduras do embasamento são todas para uso comercial. A primeira à direita de quem olha da Avenida São João, demarcada por verga em arco pleno, serve de acesso para os pisos superiores. Uma segunda entrada, no Vale do Anhangabaú, também possui vão em arco pleno e sobreverga com bossagem adornada. Entre o térreo e o piso da sobreloja há entablamento contínuo. No primeiro e terceiro andar no chanfro há presença de muxarabiês em madeira. Algumas das envasaduras possuem guarda-corpo em ferro com serralheria artística. As esquadrias são em madeira e vidro. Entre o terceiro e quarto andar há outro entablamento contínuo simples. 0 quarto andar (ático) possui área construída menor que os demais, devido ao recuo para o interior do lote, que é utilizado como um terraço (fechado posteriormente). Nos vãos das janelas deste andar, e na pequena varanda há presença dos balcões com pequenos arcos sobrepostos considerados um detalhe característico do estilo Neocolonial. 0 ático possui cimalha e platibanda, tendo este um acabamento diferenciado no chanfro e um destacado frontão adornado com volutas no eixo central da fachada para o Vale do Anhangabaú.

O engenheiro português Ricardo Severo, autor do projeto, foi um dos principais expoentes do neocolonial no Brasil tanto para projetos comerciais quanto para residências da elite. 
UM PERCURSO DE CONHECIMENTO Evantarestos netrace oncto r oertai METODOLOGIA DE LEVANTAMENTOS PARA PROJETOS DE RESTAURO AROUITETONICO E URBANO

\begin{abstract}
NuVEM de PONTOS MESHO E DESENVOLVMento oe OESENAS
\end{abstract}
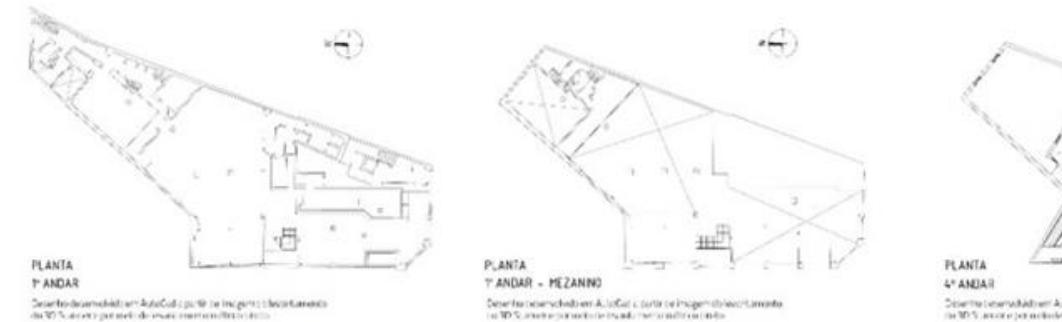

Thaneat $\sin _{i \rightarrow n}$
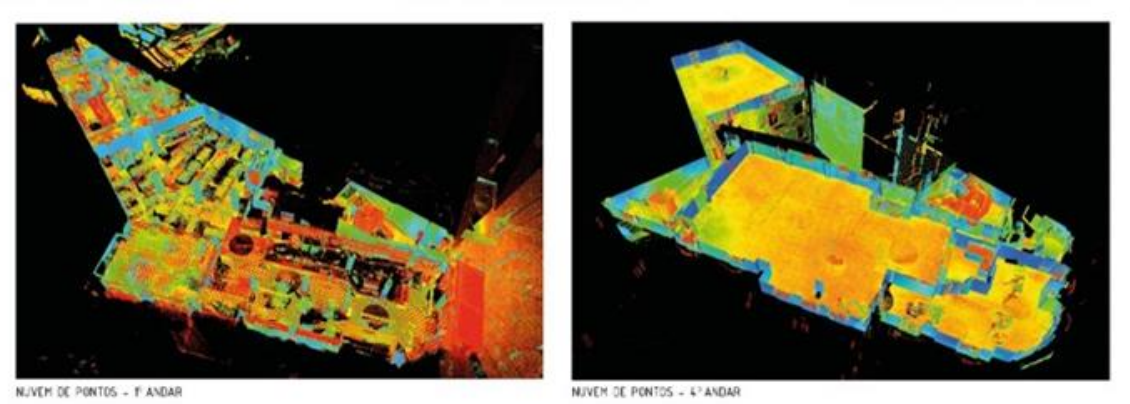

$$
4 / 8 \text { LABORATório de LEVANTAMENTO Digital COM }
$$
ARQUITETÓNILO E URBANO
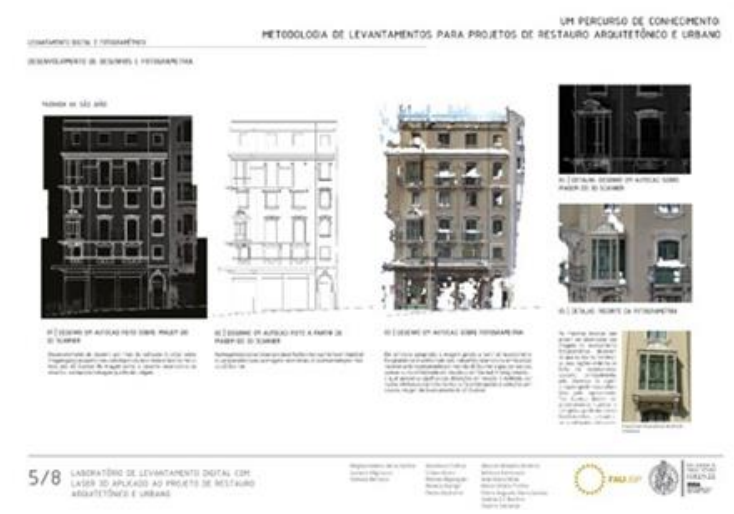

Figura 5. Parte dos resultados da disciplina experimental 2017, estudo de caso o Edifício Baraúna.

\section{Fonte:}

Acervo da Pesquisa.

O trabalho teve como objetivo reconstruir aspectos da história das técnicas construtivas e da indústria da construção na cidade de São Paulo, que raramente podem ser percebidos no tecido urbano atual. Como se depreende do relato anterior, os edifícios históricos sofreram diversos graus de transformações, mas, muitas vezes, ainda apresentam a caracterização original, com decorações e artefatos de interesse, no entanto, mal preservados ou restaurados com materiais não adequados aos critérios de conservação mais atualizados.

O estudo visa contribuir para a história da urbanização da cidade e pretende, na sua evolução futura, oferecer um exemplo de documentação para intervenções de restauro e reutilização para usos compatíveis com as necessidades do século XXI. 


\section{A FILIAL DO GRAND HOTEL NO LARGO DO CAFÉ}

Figura 6. A) À esquerda, vista do Largo do Café, fotografado por Guilherme Gaensly, 1911. Fonte: BARBUY Heloisa, A cidade-exposição. Comércio e cosmopolitismo em São Paulo 1860-1914, São Paulo, EDUSP, 2006, p. 100

B)À direita, fachada do edifício da antiga sucursal do Grande Hotel no Largo do Café, 2018. Fonte: Foto Regina Helena Vieira Santos.
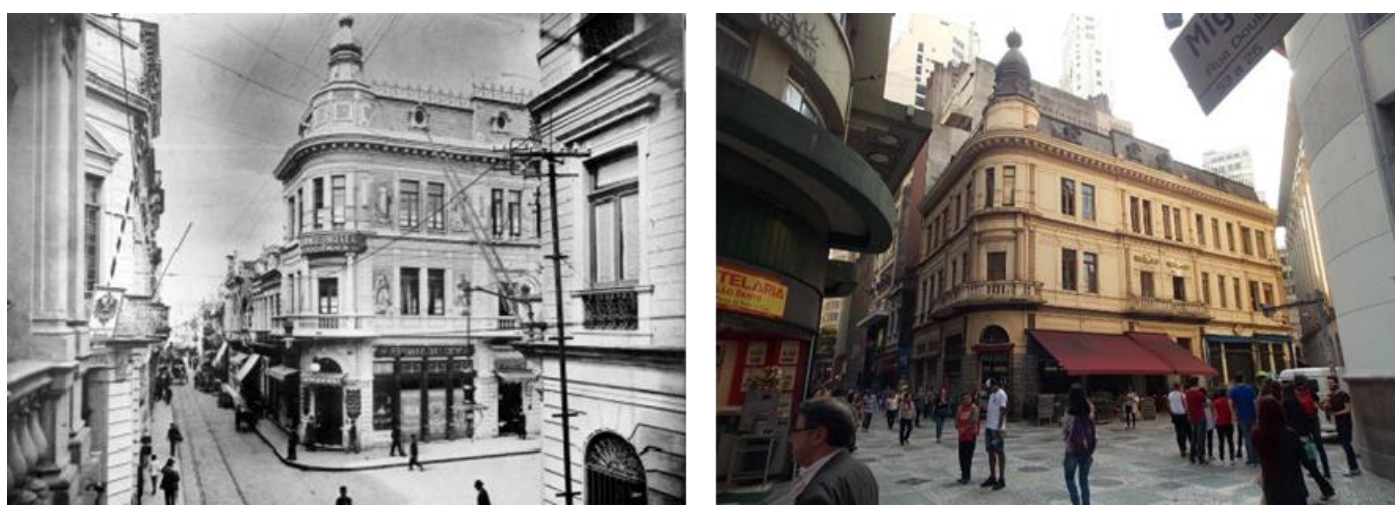

No centro de São Paulo a Rua São Bento liga o Largo de São Bento ao Largo de São Francisco e forma parte do chamado "triângulo histórico" das ruas da cidade, junto com a Rua Direita e a Rua 15 de Novembro. A partir da segunda metade do século XIX, esta rua passou a receber os principais hotéis destinados a acolher os viajantes que chegavam à cidade pelo transporte ferroviário.

O edifício estudado, a antiga sucursal do Grande Hotel, conforme os documentos levantados no Arquivo Histórico, foi projetado para utilização comercial com lojas na cota da rua e escritórios nos dois pisos superiores. 0 empresário português Manoel Garcia da Silva, proprietário do armazém Loja do Japão e responsável pelo desenvolvimento da área residencial de São Paulo conhecida como Jardim Europa, foi o empreendedor do edifício. Posteriormente, o imóvel foi alugado pelo empresário Friedrich Glette, proprietário do Grand Hotel, para abrigar a filial deste estabelecimento.

A sede principal do Grande Hotel encontrava-se na rua São Bento à esquina com a Rua Miguel Couto (antigo Beco da Lapa, posteriormente Rua do Grande Hotel) tendo outra face para a Rua Líbero Badaró (antiga rua São José). 0 palacete da sucursal é localizado a pouca distância, na esquina das ruas São Bento com Alvares Penteado (antiga Rua do Comércio), e da Rua do Comércio (antiga Travessa do Comércio). Decorrente de legislação para abertura de espaços públicos como praças e largos, foi feito um acordo entre o proprietário e o município, segundo o qual o primeiro teria demolido um edifício existente no local do atual Largo do Café, em troca da anistia de uma dívida fiscal. A cartografia histórica da cidade de São Paulo analisada confirma que o atual Largo do Café foi aberto em coincidência com a construção do prédio entre 1907 e 1911.

Os desenhos arquitetônicos originais das plantas e das fachadas, com data 1907 e carimbo do arquiteto Oscar Kleinschmidt, apresentam uma edificação sem recuos para as vias. No novo edifício foi anexada uma construção já existente para a rua São Bento. No entanto, não foi possível precisar a data deste evento, pois não foi encontrado nenhum documento a respeito até o momento. 0 material estudado inclui um corte esquemático da alvenaria da fachada, que mostra alteração da largura do muro para a via, sendo maior próximo da fundação e estreitando-se a cada pavimento conforme à altura. É possível ver a platibanda que oculta a calha do escoamento das águas pluviais 


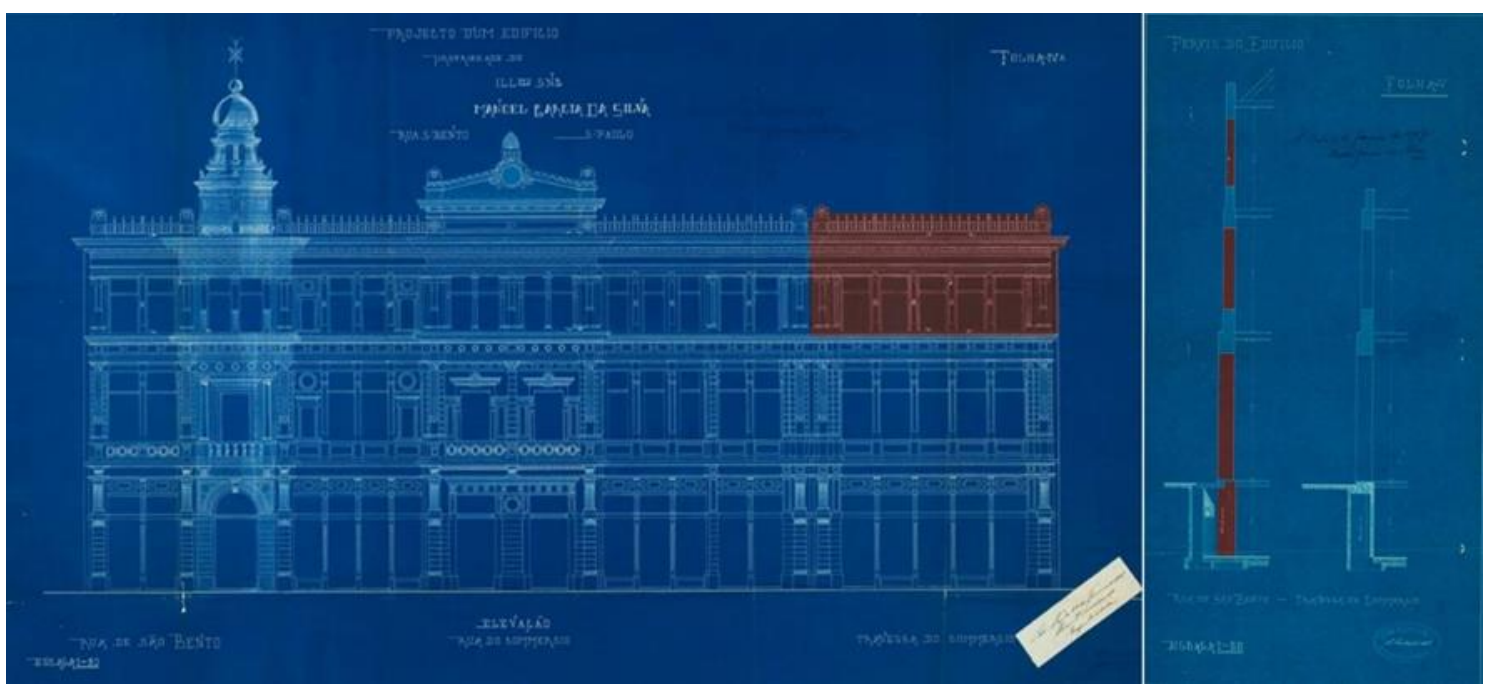

Figura 7. Desenho original fachadas e corte, 1907. Fonte: AHSP-Arquivo Histórico São Paulo.

Fonte: www.projetosirca.com .$b r$
A construção combina diversas técnicas construtivas, utilizando paredes de apoio em alvenaria de tijolos comuns à época junto a perfis e vigas metálicas de sustentação dos pisos. A utilização da alvenaria de tijolos nas paredes divisórias internas permitiu a alteração do uso dos escritórios transformados em quartos de hotel nas primeiras décadas do século $\mathrm{XX}$, e posteriormente, a remoção destes muros conforme outras necessidades de uso. 0 edifício foi aprovado seguindo o Código de Posturas de 1875, reeditado em 1886, e os desenhos realizados, em conformidade às normas municipais obrigatórias a partir de 1893. Tal código especificava altos pés direitos para boa circulação do ar, e determinava a largura das paredes, das envasaduras, das portas e das janelas, em relação à altura dos edifícios. Os vãos ainda possuem seus fechamentos de madeira, com ornamentos de metal, molduras e vitrais, nos andares superiores, preservando o desenho original. Por haver as marcas gravadas nas estruturas de ferro, foi possível verificar que elas foram produzidas em São Paulo, na Fundição do Brás pertencente ao Coronel Francisco Amaro.

0 hall de acesso atual preserva a escada original de madeira, revestida com piso frio, e o elevador original. Carece um projeto de adequação do imóvel existente para as novas normas de segurança de incêndio e acessibilidade, conservando suas características históricas.

0 telhado original era provavelmente de telhas de ardósia; atualmente encontra-se com telha de amianto conforme registros fotográficos realizados com o drone.

Analisando os desenhos das fachadas vê-se um corpo dotado de um torreão à esquina da Rua São Bento e outro corpo saliente com um frontão decorado ao centro do atual Largo do Café. 0 ritmo de cheios e vazios segue também na fachada para a Rua do Comércio (antiga Travessa do Comércio). Ao nível da via, os corpos apresentam uma sequência ritmada de aberturas destinadas a servirem de entrada para ambientes de uso comercial. Os dois pavimentos superiores possuem envasaduras alinhadas com aquelas da base e o coroamento é formado por platibanda. Há balcões nos corpos destacados com os acessos para os pavimentos superiores. 
Os ornatos das fachadas, feitos com a mesma argamassa raspada do revestimento, também conhecida como pedra fingida, baseiam-se no repertório classicista. Na base do edifício destacam-se os elementos salientes ou bossagens; no corpo, o uso de elementos como colunas e pilastras caneladas, capitéis de origem greco-romana, entablamento, dentículos. Nota-se a liberdade típica do ecletismo na manipulação do vocabulário e da sintaxe clássica. Capiteis jônicos coroam fustes lisos, os dóricos e os coríntios compartilham o mesmo espaço e a simetria especular é frequentemente negligenciada. No entanto, o uso extensivo dos elementos clássicos possui um valor simbólico e ideológico evidente.

Como era comum na época, Oskar Kleinschmidt, autor do projeto, certamente se valeu de tratados acadêmicos, e de manuais ou repertórios que circulavam amplamente entre os construtores. Portanto, optar pelo sistema clássico, longe de ser uma escolha arbitrária, significou mobilizar conscientemente elementos ideológicos que conferiram dignidade à obra, dando-lhe destaque na paisagem urbana pelo seu caráter decoroso. A linguagem ornamental é adequada à definição de "palacete comercial " atribuída à época para este tipo de construção de uso misto, comercial no piso térreo e para escritórios nos andares superiores.

As fontes encontradas fornecem poucas informações sobre Kleinschmidt. Embora ele se identifique como um engenheiro-arquiteto nos documentos, não foi possível reconstruir a sua formação profissional, nem estabelecer a data de sua chegada no Brasil ou a duração de sua estada.

Figura 8. Parte dos resultados da disciplina experimental 2018 , estudo de caso o edifício da sucursal do Grande Hotel. Fonte: Acervo da Pesquisa.

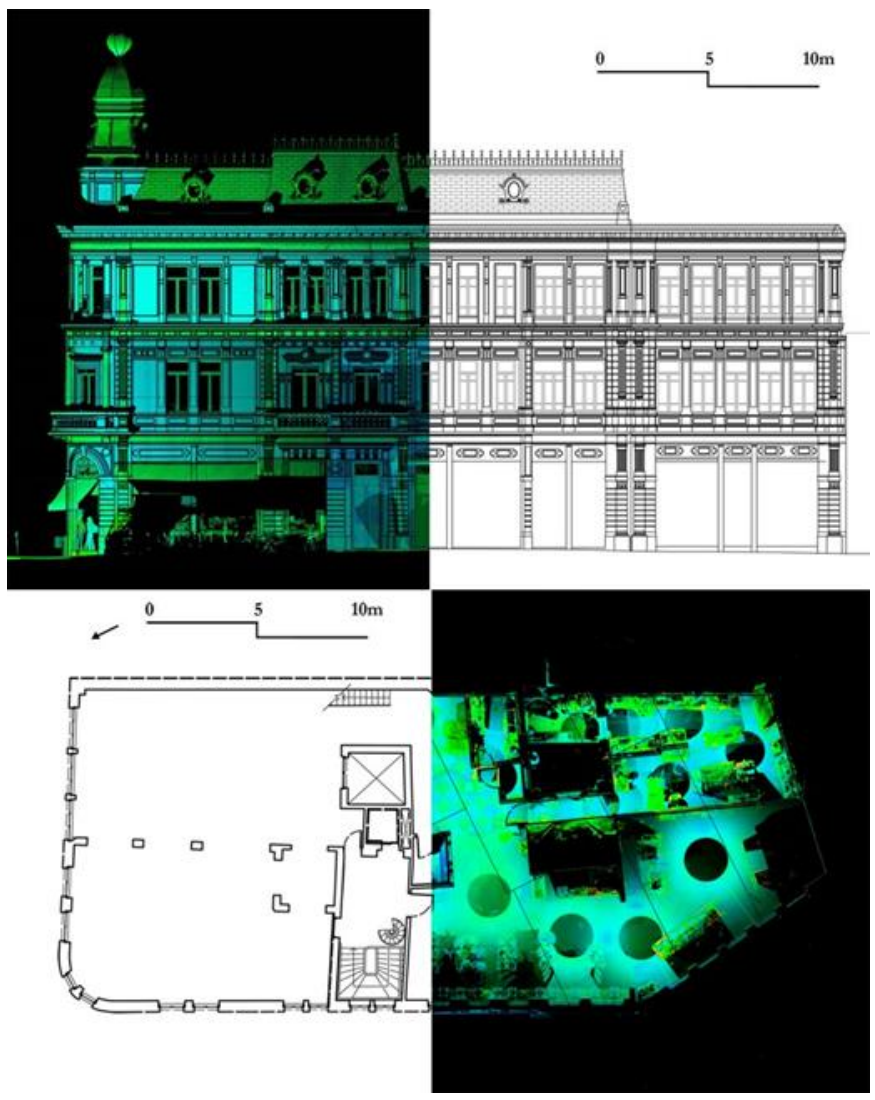




\section{O SOLAR DA MARQUESA DE SANTOS}

Em 2019, o laboratório didático contou com o importante apoio do Museu da Cidade de São Paulo e do Istituto Italiano di Cultura di São Paulo. Foi realizado pela equipe de Florença e pelos estudantes brasileiros o levantamento digital com laser scanner 3D do Solar da Marquesa de Santos, um sobrado que passou por várias fases construtivas, desde a época colonial até o final do século XIX, hoje uma das sedes do Museu da Cidade de São Paulo. 0 edifício resulta da união de duas residências localizadas na antiga rua de Santa Teresa, que se chamou depois rua do Carmo e hoje Rua Roberto Simonsen. 0 traçado desta via na São Paulo colonial ligava o Pátio do Colégio dos Jesuítas à igreja dos terciários carmelitas e à de Nossa Senhora do Carmo, hoje não mais existente. A cerca de cem metros, na mesma colina ladeada pelo rio Tamanduateí e pelo ribeirão Anhangabaú, ficavam a antiga catedral e a igreja de São Pedro dos Clérigos. Entre os séculos XVIII e XIX, a área foi ocupada por residências da elite da cidade devido à sua posição privilegiada que dava acesso para os comerciantes que desembarcavam do rio à área do Pátio do Colégio, onde estavam alguns dos principais prédios públicos: a igreja e o Colégio Jesuíta - posteriormente transformado em Palácio do Governo - a Real Casa de Fundição do Ouro e o teatro.

Segundo o cadastro para a taxação do imposto predial de 1809, a rua de Santa Teresa albergava um conjunto de edifícios de uso exclusivamente residencial: entre estes, junto do Beco do Colégio, o sobrado de número 4, de propriedade do Coronel Joaquim José Pinto de Moraes, que fora unificado ao sobrado de número 5 de propriedade do Dr. Jozé Ignácio Alvares de Castro, de acordo com os resultados das escavações arqueológicas. A documentação iconográfica revela que tal unificação aconteceu entre 1821 e 1827. O sobrado foi vendido a D. Maria Domitila de Castro Canto e Melo, Marquesa de Santos, em 1834. Tornou-se então o principal centro da incipiente vida social da capital paulista em virtude das iniciativas da proprietária, antiga favorita do imperador D. Pedro I e protagonista dos acontecimentos da política e da corte.

À época, o imóvel apresentava ainda o programa arquitetônico típico das residências aristocráticas brasileiras do período colonial: depósitos e serviços no térreo, aposentos no andar superior, tendo na frente cômodos com sacadas, destinados ao uso social, alcovas no meio e a tradicional varanda ou "sala de viver" nos fundos. Na parte de trás da casa, olhando para a Várzea do Carmo, havia um grande quintal cercado por muros de taipas de pilão, que se estendia até à beira do rio Tamanduateí, então importante caminho para o comércio em toda a região.

Domitila viveu no sobrado até sua morte em 1867. Seu herdeiro Felício Pinto de Mendonça e Castro também morou aí até falecer, em 1879, e seu espólio foi leiloado. O edifício foi arrematado pela Mitra Diocesana, em 1880, tornando-se o Palácio Episcopal. Reformas que envolveram uma mudança radical da linguagem estética do edifício foram realizadas em 1890. 0 andar térreo foi destinado às atividades administrativas, enquanto os aposentos do bispo ocuparam o andar superior. As paredes de taipa foram encamisadas de alvenaria; houve a introdução da platibanda no coroamento, ocultando o novo telhado dotado de calhas e condutores para o escoamento das águas pluviais, que substituíra o telhado com beiral da antiga construção da época colonial. 
Figura 9. a. Reconstituição da fachada dos fundos do Solar, ou seja, a vista da várzea do Tamanduateí. Feito com base na aquarela de Pallière de 1821. Autor: Henrique Andrade Reis, 2019. b. Reconstituição da fachada dos fundos do Solar. Feito com base no desenho de Francisco Sauvage, Panorama da cidade, tomado da várzea do Carmo, de 1889. Autor: Henrique Andrade Reis, 2019.

LABSAMPA - cooperação científica e tecnológica entre a Faculdade de Arquitetura e Urbanismo da Universidade de São Paulo e o Dipartimento di Architettura dell'università degli Studi di Firenze para a documentação da arquitetura histórica de São Paulo.

No pavimento térreo, foi alterada a disposição das aberturas, centralizando as três portas de acesso, em linha com o balcão superior, buscando-se criar um eixo de simetria conforme os preceitos clássicos, alinhado com a atual Rua Floriano Peixoto, antiga Rua da Fundição. Também as janelas foram dispostas simetricamente em relação ao ingresso tripartite. No pavimento superior, os vãos dos balcões receberam ornamentação, com sobrevergas curvas e frontões. 0 vão central ainda recebeu uma moldura para a exibição do brasão episcopal. A adaptação do antigo sobrado do período colonial, por meio da adoção de um repertório ornamental e de uma sintaxe compositiva classicistas, seguiu um padrão observado no restante da cidade de São Paulo e no Brasil afora, inspirado em modelos franceses e italianos.

$\mathrm{Na}$ fachada posterior, a iconografia mostra importantes alterações, como o fechamento da varanda, o acréscimo de um novo ambiente, e de uma escadaria de dois lances convergentes, ornamentada por um nicho, descendo para o quintal, que foi transformado em jardim. Dessa forma, buscou-se adequar a linguagem estética da fachada posterior aos preceitos classicistas que haviam norteado as intervenções na fachada voltada para a atual Rua Roberto Simonsen.
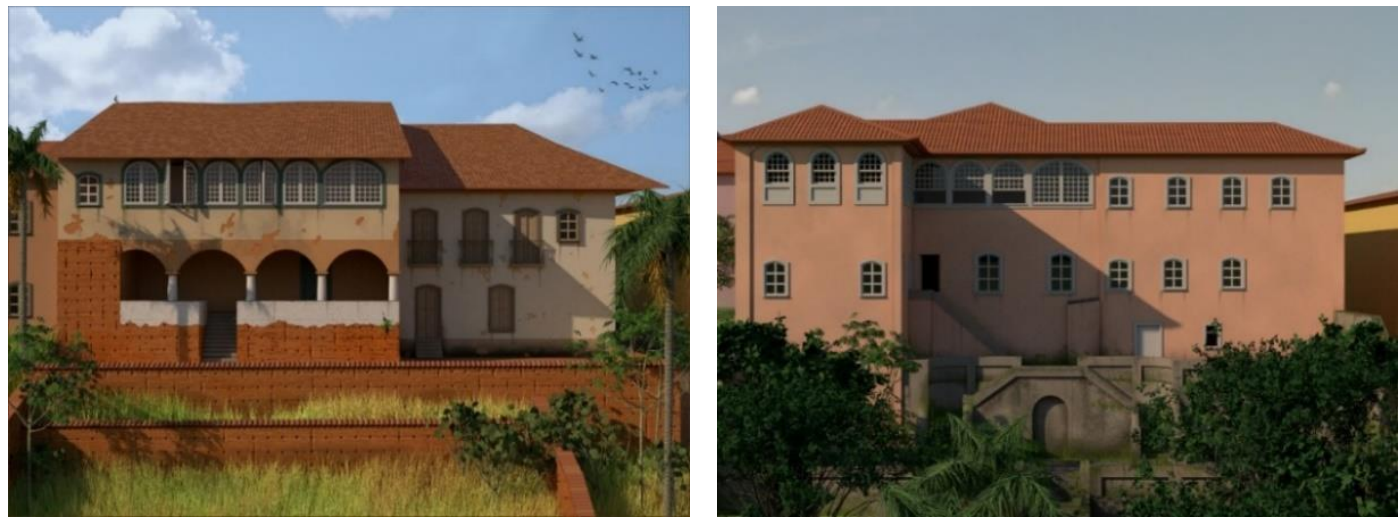

Em 1909, o imóvel foi adquirido pela Companhia de Gaz de São Paulo, que foi sua proprietária até 1967. Documentos do Arquivo Histórico de São Paulo (AHSP) com desenhos de reformas, assim como registros iconográficos, ilustram as muitas alterações realizadas do período em que o imóvel esteve sob posse da empresa. 0 andar térreo se tornou um espaço único de uso comercial, enquanto as aberturas na fachada foram transformadas em vitrines. Estudos arqueológicos realizados na década de 1990 demonstram que houve elevação do nível do piso do térreo, para que não ficasse ao nível da rua, conforme exigido pela legislação então vigente. É provável que as colunas metálicas hoje existentes na mesma área, parcialmente encamisadas com alvenaria de tijolos, datem desse mesmo período. 0 pavimento superior foi alterado para se tornar a residência do gerente da companhia.

Entre 1934 e 1939, aos fundos, em parte do espaço do quintal, foi construído um anexo com nova tipologia e técnica construtiva se utilizando o concreto armado. No ano de 1967, o edifício foi desapropriado e em 1971 foi reconhecido no livro de tombo do Conselho de Defesa do Patrimônio Histórico, Arqueológico, Artístico e Turístico (CONDEPHAAT), passando a pertencer à Prefeitura Municipal a partir de 1975, como sede da Secretaria Municipal de Cultura. 
Um estudo realizado pelo arquiteto Carlos Alberto Cerqueira Lemos, publicado em 1968, nos informa sobre os diversos materiais, técnicas e sistemas construtivos utilizados, embasando as propostas de restauro que foram posteriormente aprofundadas pelo arquiteto Alexandre Luiz Rocha. 0 imóvel foi restaurado em 1991 conforme os princípios das cartas de restauro, deixando à vista as diferentes técnicas construtivas encontradas nas prospecções feitas, assim como os registros arqueológicos. Desta forma, foi possível ilustrar também as noções de preservação e restauro que nortearam as intervenções ao longo do tempo.

Os resultados obtidos por meio da experiência do levantamento com laser scanner 3-D integrado com as metodologias já mencionadas, mesmo num edifício histórico muito estudado, ofereceram a possibilidade de verificar e precisar os estudos já realizados. Ainda, por meio das formas de representação gráfica baseadas na combinação dos resultados da nuvem de pontos e das informações fornecidas pela fotogrametria a respeito das texturas e das cores, foi possível pensar na aplicação da modelagem tridimensional no campo da comunicação e da mediação cultural em função didática e formativa no âmbito dos museus.

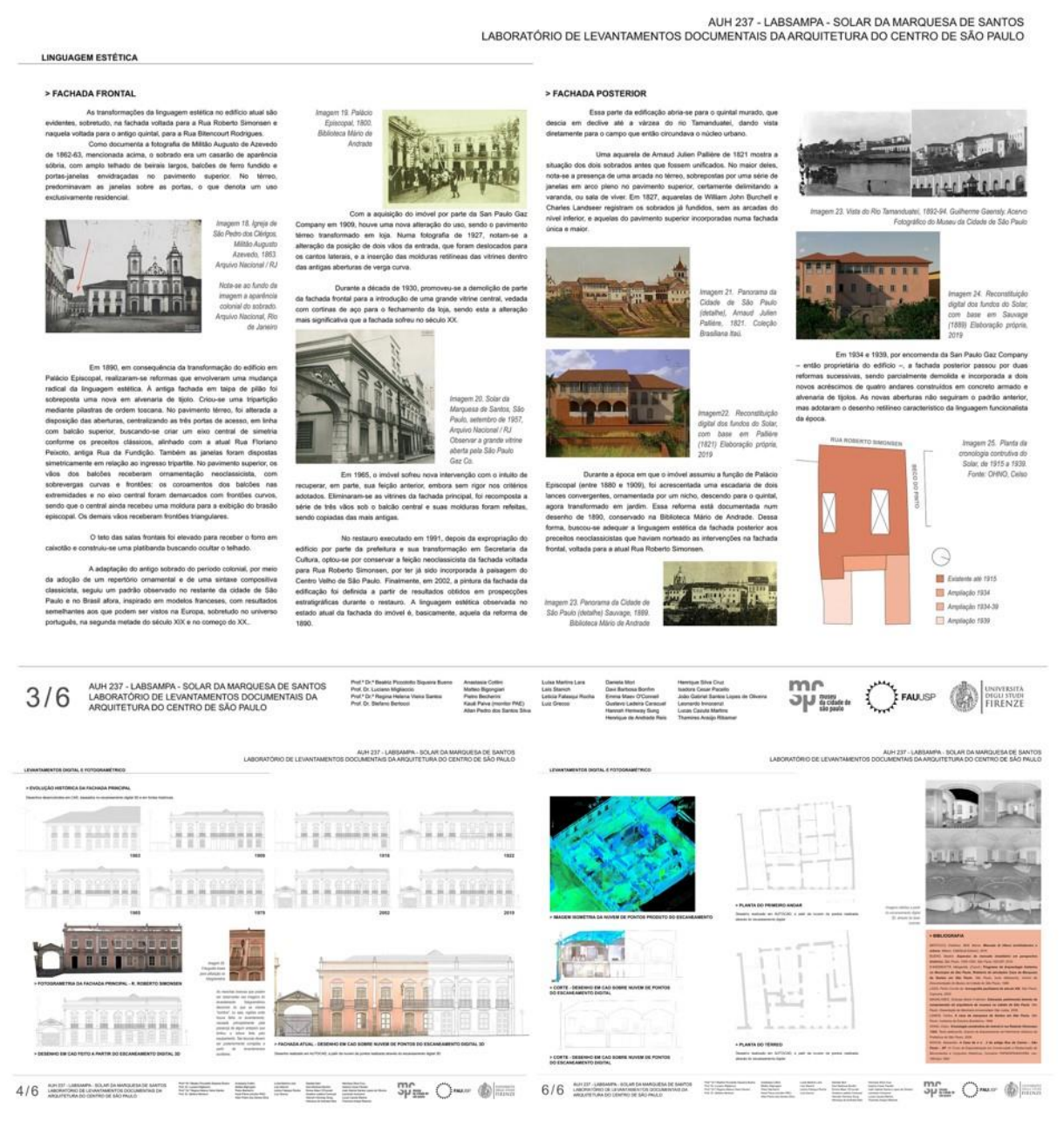

Figura 10. Parte dos resultados da disciplina experimental 2019, estudo de caso o Solar da Marquesa de Santos, antigo sobrado número 3 da Rua do Carmo.

Fonte:

Acervo da Pesquisa. 


\section{CONCLUSÕES}

Os casos apresentados mostram a variedade de situações, de contextos, de intervenções presentes na história de inúmeros edifícios, muitos ainda não considerados pela ação de catalogação e de preservação do poder público. Devido à rápida dinâmica da transformação do patrimônio edificado no centro de São Paulo, muitos entre eles serão submetidos a novas iniciativas de reutilização com inevitáveis efeitos de descaracterização e, muitas vezes, de degradação.

O uso da metodologia integrada da equipe do Dipartimento di Arquitetura da Università di Firenze, liderada pelo prof. Bertocci, ao longo das atividades de cooperação acadêmica e científica, permitiu aos alunos da FAU USP familiarizar-se com os procedimentos da tecnologia do levantamento digital com laser scanner 3-D e perceber o seu valor na formação do arquiteto para a documentação histórica da arquitetura em função da preparação de corretas ações de planejamento urbano, de preservação, restauro, reutilização bem como de mediação cultural.

Além desta sólida aquisição no campo do conhecimento e da formação, a metodologia começa a ser aplicada concretamente, com resultados muito promissores em Trabalhos Finais de Graduação, e em pesquisas de Pós-graduação. São exemplos desta cooperação acadêmica que poderá desembocar em acordos de dupla titulação, além do Doutorado já defendido da Dra. Regina Helena Vieira Santos, o Trabalho final de Lais Stanich sobre o Edifício Baraúna, orientado pela profa. Beatriz Bueno, a ser defendido em março de 2021, e a pesquisa de doutorado de Rodrigo Minot Gutierrez sobre os desenhos de arquitetura do Barroco Mineiro, orientado pelo prof. Artur Rozestraten, ainda em andamento.

Por sua vez, a iniciativa promoveu um renovado interesse dos alunos e dos pesquisadores italianos em relação à história da arquitetura e das cidades brasileiras, inclusive, em relação a períodos menos valorizados pela historiografia. Sob este aspecto, cabe salientar as teses de Anastasia Cottini e Chiara Alessi sobre o levantamento das fachadas dos prédios de um trecho da Avenida São Jõao em São Paulo, já defendidas junto ao Dipartimento di Architettura dell'Università di Firenze, com a colaboração da Dra. Vieira Santos.

Neste ano de 2020, as difíceis condições determinadas pela pandemia de Covid-19, impediram à equipe italiana de participar de forma presencial da disciplina LabSAMPA. Malgrado este inconveniente, o projeto de cooperação, além do Dipartimento de Arquitetura de Florença, e do Museu da Cidade de São Paulo, passará a incluir outro parceiro de grande relevância, isto é, o CITI (Centro Interdisciplinar em Tecnologias Interativas da USP) dirigido pelo prof. Marcelo Knorich Zuffo. 0 centro destaca-se pela excelência da pesquisa em tecnologias imersivas com competência multidisciplinar que envolve a modelagem tridimensional e procedimentos de catalogação digital no campo dos bens culturais.

Uma contribuição importante desta experiência de cooperação, a nível educacional, foi a abordagem a novas tecnologias atualmente disponíveis em número cada vez maior, e à expansão do campo de aplicações específicas no setor de levantamento arquitetônico, conservação e restauração, que impõem novos desafios ao tradicional referencial científico e cultural do setor. Em particular no contexto do levantamento digital, do sensoriamento remoto à escala arquitetônica e urbana, houve contribuições importantes para otimizar a gestão da complexidade dos dados que emergem da abordagem científica à documentação da realidade da arquitetura e da cidade histórica e contemporânea. 
A difusão e evolução exponencial das tecnologias de informação e comunicação (TIC), em particular, no setor de patrimônio, tem levado ao desenvolvimento cada vez mais extenso de aplicativos e ferramentas digitais para visualização e fruição de tudo o que normalmente vem definido como bem cultural. 0 curso, portanto, levou a experimentar uma melhor organização dos dados e dos conhecimentos, de maneira que, através do uso da tecnologia como real extensão da inteligência humana, seja possível contribuir para um mais efetivo conhecimento do patrimônio a ser protegido.

Com o aporte das novas metodologias da gráfica e da modelagem digital, além daquelas já aplicadas nos laboratórios teórico-práticos até hoje realizados, será possível aos alunos fazerem experiências que passam do nível dos edifícios ao dos objetos virtuais. A tecnologia pode permitir, por exemplo, a exposição de produtos digitais a partir dos fragmentos encontrados nas escavações arqueológicas realizadas no território urbano, hoje conservados no acervo do Centro de Arqueologia do Sítio Morrinhos - Santana. Integrando a pesquisa dos arqueólogos e os levantamentos documentais dos arquitetos e dos historiadores, espera-se poder apresentar ao público dos museus a cultura material dos indígenas e do início do período colonial, hoje escondida sob as estratificações urbanas modernas, tanto na metrópole quanto no litoral paulista.

Os resultados do levantamento efetuado com as diferentes metodologias e técnicas, aliado à análise histórica e a formas de comunicação adequadas, permitirão ao público perceber o valor dos edifícios e dos objetos como documento de processos tecnológicos e de produção, de conflitos existentes na história social, da política urbana, da mentalidade, do gosto, e suas relações recíprocas. A tecnologia digital, através de novas formas de mediação e de comunicação, pode transformar a relação da universidade com o ensino e com o público externo, permitindo a síntese de diferentes tipos de informação, auxiliando para desenvolver um novo conceito, mais democrático, de gestão territorial que preserve os valores históricos e da memória cultural no planejamento das transformações da grande metrópole brasileira.

\section{Coleções consultadas}

Arquivo Histórico de São Paulo (AHSP). Série de obras privadas.

Acervo do Arquivo Histórico Municipal de Washington Luís.

Biblioteca digital de jornais: Biblioteca Nacional (RJ): Correio Paulistano século XIX e início do século XX. <http: // bndigital.bn.gov.br/hemeroteca-digital/>

Coleção Arquivo DESAP - Departamento de Expropriação

Arquivo do Departamento de Projetos de Infraestrutura Urbana

\section{Referências bibliográficas}

ALAMBERT, Clara Correia d '. O tijolo nas edificações paulistas do século XIX. San Paolo: Mestre FAUUSP, 1993.

AMERICANO, Jorge. (2004). São Paulo nasceu na época (1895-1915). São Paulo: Carrrenho Editorial; Narrativa Um; Carbono 14.

BARBUY, Heloisa. A Cidade - Exposição. Comércio e cosmopolitismo em São Paulo, 1860-1914. São Paulo: EDUSP, 2006.

BERTOCCI, Stefano. BINI, Marco. Manuale di rilievo architettonico e urbano. Milano: CittàStudi Edizioni, 2016. 
LABSAMPA - cooperação científica e tecnológica entre a Faculdade de Arquitetura e Urbanismo da Universidade de São Paulo e o Dipartimento di Architettura dell'università degli Studi di Firenze para a documentação da arquitetura histórica de São Paulo.

BERTOCCI, Stefano; PARRINELLO, Sandro. Digital Survey and Documentation of the Archaeological and Architectural sites. Firenze: Edifir, 2015.

BERTOCCI, Stefano; MINUTOLI, Giovanni; MORA, Susana; PANCANI, Giovanni. Complessi religiosi e sistemi difensivi sul cammino di Santiago de Compostela: rilievi e analisi per la valorizzazione e il restauro della catedrale di Santa Maria la Real a Sasamón. Firenze: Centro Stampa del Consiglio Regionale della Toscana, 2015.

BUENO, Beatriz Piccolotto Siqueira. "Desenhar" (projetar) em Portugal e no Brasil nos séculos XVI-XVIII. Cadernos de Pesquisa do LAP, 36, FAUUSP, 2003.

BUENO, Beatriz Piccolotto Siqueira. A cidade como negócio: mercado imobiliário, projetos e processo produtivo do centro antigo de São Paulo do século XIX à lei do arrendamento (1809-1942). São Paulo: Tese de Ensino Gratuita da FAUUSP, 2018.

BUENO, Beatriz Piccolotto Siqueira. São Paulo: um novo olhar para a história: a evolução do comércio varejista e as transformações da vida urbana. [SI: sn], 2012.

CAMPOS NETO, Candido Malta. Os rumos da cidade. Urbanismo e Modernização em São Paulo, São Paulo: SENAC, 2002.

CARBONARA, Giovanni. Architettura d'Oggi e restauro. Um confronto ântico-nuovo. Torino: UTET, 2011.

CORONA, Eduardo; LEMOS, Carlos Alberto Cerqueira. Dicionário Brasileiro de Arquitetura. [Ps: sn], 1989.

DA COSTA, Cacilda Teixeira. Sonho e técnica: Arquitetura do Ferro no Brasil. São Paulo: EDUSP, 2001.

DOCCI, Mario; MAESTRI, Diego. Manuale di rilevamento architettonico e urbano. Bari: Editori Laterza, 2009.

FARNETI, Fauzia (ed.). Naso, terra grande, ricca ed antica. Tessuto urbano e architettura dal cinquecento al novecento. Firenze: Alinea, 2012.

FARNETI, Fauzia. Naso. Guida alla visita della città. Firenze: Alinea, 2009.

FARNETI, Fauzia. Naso: tre secoli di storia. Architettura, arte e terremoti. Firenze: Alinea, 2006

KÜHL, Beatriz Mugayar. Arquitetura do ferro e arquitetura ferroviária em São Paulo: reflexões para sua conservação. São Paulo: FAPESP, 1998.

LEFEVRE, José Eduardo de A. (2006). De beco em avenida. A história da Rua São Luiz. São Paulo: EDUSP.

LEFEVRE, José Eduardo de A. (2003). Desafios das áreas centrais da cidade de São Paulo: ou caso da Avenida São João. LISBOA: Laboratório de Engenharia Civil.

LEMOS, Carlos Alberto Cerqueira. O álbum de Afonso. A reforma de São Paulo. São Paulo: Pinacoteca do Estado, 2001.

LEMOS, Carlos Alberto Cerqueira. Alvenaria Burguesa. São Paulo: Studio Nobel, 1989.

LEMOS, Carlos Alberto Cerqueira. A casa da marquesa de Santos em São Paulo. São Paulo, Institutos de Estudos Brasileiros, 1968.

MELLO, Joana. Ricardo Severo: da arqueologia portuguesa à arquitetura brasileira. São Paulo: Annablume Fapesp, 2007.

MEURS, Paul. Engenho São Jorge dos Erasmos: Estudos de Preservação. Cadernos de Pesquisa do LAP, 07, FAUUSP, 1995.

NOBLE, André; VALENTIN, Jailson. Elementos funcionais e ornamentais das fachadas ecléticas do Pelotan: $1970-$ 1931. Emplastros. Santa Catarina: Centro de Artes da UFPEL.

PETRELLA, Yara Lígia MM; PINHEIRO, Maria Lucia Bressan. Museu Paulista: edifício que utiliza técnicas tradicionais de construção em alvenaria. 2008. Universidade de São Paulo, São Paulo, 2008.

Disponível em: 
<http://www.tese.usp.br/tese/disponiveis/16/16133/tde-11112010-153603/?\&lang=pt-br>.

PINHEIRO, Maria Lúcia Bressan . Neocolonial, Modernismo e Preservação do Patrimônio no Debate Cultural dos Anos 1920 no Brasil . São Paulo: EDUSP / Fapesp, 2011.

REIS FILHO, Nestor Goulart, Quadro da arquitetura no Brasil. São Paulo: Perspectiva, 1970.

REIS FILHO, Nestor Goulart. San Paolo Vila Cidade Metrópole. São Paulo: Takano Editora Gráfica, 2004.

ROCHA, Alexandre. A Casa de no. 3 da antiga Rua do Carmo - São Paulo - SP. IV Curso de Especialização em Conservação e Restauração de Monumentos e Conjuntos Históricos, Convênio FNPM/SPHAN/UFBA, nov. 1981/jun.1982.

SALMONI, Anita. DEBENEDETTI, Emma. Arquitetura italiana em São Paulo. San Paolo: Perspectiva. 1981.

SANTOS, Regina Helena Vieira. Rua São João: o Boulevard paulistano da Primeira República (1889-1930). Tese de Doutorado, FAUUSP, 2017.

SANTOS, Regina Helena Vieira. Rua São Bento: Um fragmento da cidade de São Paulo que registra as transformações e persistências na paisagem urbana. Dissertação de Mestrado, FAUUSP, 2008.

SEGAWA, Hugo Massaki. Arquiteturas no Brasil 1900-1990. São Paulo: EDUSP, 2 a. edição, 2002.

SEGAWA, Hugo Massaki. Prelúdio da Metrópole. São Paulo: Editorial Ateliê, 2004.

SIMÕES JUNIOR, José Geraldo. Anhangabaú: história e urbanismo. São Paulo: SENAC/Imprensa Oficial do Estado de São Paulo, 2004.

TOLEDO, Benedito Lima de. Prestes Maia está nas origens do urbanismo moderno em São Paulo. São Paulo: Empresa das Artes, 1996.

TOLEDO, Benedito Lima de. Anhangabahú. São Paulo: Federação das Indústrias do Estado de São Paulo, 1989.

TOLEDO, Benedito Lima de. São Paulo: três cidades em um século. São Paulo: Duas Cidades, 1981

SANTOS, Regina Helena Vieira. Rua São Bento: um fragmento da cidade de São Paulo que registra as transformações e persistências na paisagem urbana. São Paulo: tese de graduação da FAUUSP, 2008.

SANTOS, Regina Helena Vieira. Rua São João: a avenida São Paulo da Primeira República (1889-1930). San Paolo: Tese de Doutorado da FAUUSP, 2017.

SUMMERSON, John Newenham. Linguagem clássica da arquitetura. São Paulo: Martins Fontes, 2006.

VAN RIEL, Silvio. Ficarra, identità urbana e architettonica. Ricerche e materiali per la valorizzazione e il restauro. Firenze: Alinea, 2011. 